\title{
Representações do capitalismo em Chapetuba Futebol Clube, de Oduvaldo Vianna Filho
}

Luiz Paixão Lima Borges*

\section{Resumo}

Chapetuba Futebol Clube, primeira peça teatral de Oduvaldo Vianna Filho - Vianninha - encenada pelo Grupo de Teatro Arena, marcou época por seu valor dramatúrgico e por sua importância na análise da realidade social brasileira. No presente trabalho, visando a ultrapassar a crítica tradicional, que percebe apenas no binômio suborno/corrupção no futebol o reflexo da sociedade, discutimos as configurações dos mecanismos de opressão capitalista apontados pelo dramaturgo. Como método de análise, utilizamos a crítica materialista e dialética, amparada nos estudos de Lukács e Adorno, visando a estabelecer a relação de mútua determinação entre arte e sociedade, tendo no condicionamento histórico as bases da configuração artística. Chapetu$b a$ investe no realismo crítico como alternativa estética e formal para tentar compreender um instante de profundas mudanças sociais, políticas e econômicas ocorridas na segunda metade dos anos 1950, caracterizadas como "nacional desenvolvimentismo". $\mathrm{Na}$ peça, o futebol não é visto apenas como paixão corrompida e manipulada pelo dinheiro, embora este seja o seu tema: a discussão recebe também tratamento diferenciado, tanto política quanto ideologicamente, pois pretende trazer para o debate a configuração social frente aos poderosos mecanismos de persuasão e coerção econômica do sistema capitalista em nosso país.

Palavras-chave: Dramaturgia brasileira. Oduvaldo Vianna Filho. Teatro engajado.

\section{Introdução}

A ação política do movimento teatral brasileiro, na segunda metade da década de 1950, pautou-se por uma profunda busca da identidade nacional e entendimento das relações sociais e formas de luta do

Doutorando em Estudos Literários na Faculdade de Letras da Universidade Federal de Minas Gerais. E-mail: luizpaixaoteatro@gmail.com

Data de submissão: jan. 2018 - Data de aceite: fev. 2018 http://dx.doi.org/10.5335/rdes.v14i1.7281 
povo. O teatro, assim como toda a arte e a cultura brasileiras, em suas mais diversas formas de expressão, foi contagiado pela euforia "juscelinista" e respondeu positivamente em suas responsabilidades sociais. Como se pode constatar, o "nacional desenvolvimentismo" não prevaleceu apenas na indústria e setores da economia formal. As liberdades democráticas formaram um solo fértil para uma diferenciada manifestação do saber e do fazer. As novas perspectivas, implantadas pelo governo JK, criaram condições objetivas e subjetivas para uma ação cultural e artística diferenciada e contaminaram o espírito daqueles que acreditavam na afirmação e no crescimento do país.

O momento é rico em debates políticos e ideológicos em torno da função do teatro. A certeza da necessidade de um teatro atuante e participativo é marcante na formação do grupo amador Teatro Paulista do Estudante (TPE). ${ }^{1}$ As presenças de Oduvaldo Vianna Filho e Gianfrancesco Guarnieri, ambos militantes ativos do PCB, são fundamentais para a formulação da orientação política do grupo e podem ser confirmadas em importante documento produzido pelo TPE:

[...] os problemas da cultura não vivem independentemente de problemas políticos e econômicos. Um povo entorpecido é um povo que na passividade se encontre à rapina $\mathrm{e}$ à escravidão. Um povo entorpecido é o que não ama, não quer, não luta. E a cultura destinada a entorpecer um povo é aquela que se desliga desse mesmo povo, que se desvencilha de seus sentimentos, paixões e aspirações, é a que foge dele, é a que se abstraindo do humano, deturpa e entorpece (1978 apud MOSTAÇO, 1982, p. 28-29).
O encontro do grupo amador com o Teatro de Arena, em 1956, e sua posterior fusão parecem-nos naturais, considerando que os objetivos dos dois grupos apontavam numa mesma direção; as afinidades políticas e ideológicas se projetavam na formulação de uma estética que buscava o realismo social e crítico como opção. A necessidade de ampliação do raio de influências do $\mathrm{PCB}$, por meio de dois de seus militantes - Vianninha e Guarnieri -, encontra no Arena o campo fértil para se desenvolver e, ali, implementar uma reflexão ainda mais qualificada ideologicamente.

As pesquisas desenvolvidas pelo Arena - visando à constituição estética de um modelo - que estabeleciam como objetivo principal a reflexão sobre as condições de vida do homem brasileiro, e a própria sociedade enquanto sistema econômico, político e social, estão inseridas num momento decisivo para a própria história do país. Oduvaldo Vianna Filho, em artigo de 1958, detecta a importância desse momento ímpar e, ao discutir a contradição entre "um teatro comercial ou um teatro brasileiro", aponta as perspectivas de transformações que orientam o novo fazer teatral:

O teatro brasileiro atravessa já uma das fases mais expressivas de todo o seu desenvolvimento histórico. A da definição. Fase da conscientização diante de realidade que não pode mais ser ignorada. [...] um teatro nacional. Um teatro que procure a realidade brasileira que apreenda o sentido do seu desenvolvimento e que lute ao lado dele (PEIXOTO, 1983, p. 23-24). 
O Arena não é apenas uma experiência estética; é, também, uma experiência política e ideológica: sua pesquisa, que tem como referência a realidade social do país, observa a aplicação dos conceitos materialistas de análise e a formalização estética. Colocando-se em rota de confronto com a realidade cênica dominante, propõe uma ruptura que se ramifica nos diversos aspectos do espetáculo: dramaturgia, encenação e interpretação dramática.

O exercício teórico sistemático, implementado pelo grupo a partir da parceria com o TPE e acentuado com a adesão de Augusto Boal, promove modificações estruturais em sua organização. O Arena deixa de ser apenas uma companhia que encena espetáculos e adota uma postura que 0 define como um espaço privilegiado para uma discussão qualificada sobre o fazer teatral e as condições sociais vigentes. Tal experiência se apresenta como um embrião que irá definir os rumos dos seminários de dramaturgia, quando será aprofundada.

Pela primeira vez defrontamo-nos com uma companhia teatral preocupada em encontrar nas relações sociais aspectos, modos e temas, tornando-os matéria da ação cênica. A pesquisa de um teatro vai se afirmando cada vez mais como veículo de inquietação e transformação na permanente investigação de processos de aproximação com a realidade objetiva. Não apenas é uma aproximação por meio da empatia com o herói, mas também se manifesta a partir dos conflitos gerados na luta pela resolução da contradição básica entre suas necessidades e suas possibilidades, uma aproximação para compreensão e transformação dessa mesma realidade, cujo objetivo final é sua superação.

\section{Seminário de dramaturgia}

Bertolt Brecht afirma que, "sem introduzir inovações de tipo formal, a literatura não pode apresentar novos conteúdos e novos pontos de vista para novas camadas do público" (FISCHER, 1983, p. 131), e acrescenta: "a realidade se modifica: para representá-la, é necessário modificar também os meios de representação" (BRECHT, 1967, p. 119). Existe, portanto, uma relação dialética entre realidade e sua representação artística, que sempre será dinâmica em sua interação. A definição por uma forma que melhor traduza interesses específicos está condicionada à especificidade do momento histórico em que é produzida. $\mathrm{Ou}$, como bem acentuou Lukács:

É o fato de uma obra literária se fundar em uma concepção correta das realidades sociais e históricas que lhe permite, por um lado, assumir um valor autenticamente realista e, por outro lado, constituir um fator particular e insubstituível da influência que ela deve normalmente exercer; mas, de qualquer destes pontos de vista, nunca um conhecimento teórico do mundo, do homem, etc., poderia inspirar o escritor, a não ser quando se incorpora inteiramente em categorias estéticas e quando se deixa totalmente absorver por elas. [...] para o escritor, efetivamente, nenhuma teoria, nenhum saber, tem outra função que não seja ajudá-lo a descobrir uma maneira mais profunda de refletir o real no próprio plano da arte (LUKÁCS, 2010, p. 141). 
A montagem da peça Eles não usam black-tie, de Gianfrancesco Guarnieri, em 1958, demonstrou que era possível se construir uma dramaturgia brasileira que apresentasse camadas sociais ainda não representadas em cena. Um novo teatro se configurava irreversivelmente, o nacional e o popular como operadores do novo modelo dramatúrgico respondiam às necessidades de um momento histórico, que encontrava o país aberto e receptivo aos questionamentos propostos tanto no campo social quanto no político e no ideológico.

Chapetuba Futebol Clube, primeira peça produzida como resultado das discussões do Seminário de Dramaturgia do Teatro de Arena, aberto em abril de 1958, marcaria não só o lançamento de Oduvaldo Vianna Filho como dramaturgo, mas, sobretudo, a fixação do autor no teatro brasileiro, demonstrando, com isso, o acerto da opção do Arena em investir numa dramaturgia de cunho eminentemente nacional, assim como a concretização de um projeto estético-ideológico, que se tornaria referência no teatro nacional. A proposta de um teatro de caráter popular, tanto em sua dramaturgia e sua encenação quanto em sua expectativa de estabelecer novas relações com o público, procurava "analisar os problemas sociais do Brasil com uma nova visão, enfocando as classes menos privilegiadas, sob seu próprio ponto de vista" (DIONYSOS No. 24, 1978, p. 77). Os membros do grupo perseguiam de maneira quase obsessiva a afirmação da identidade nacional, o que começa a se concretizar com a realização do seminário.

O teatro se transformava para transformar a realidade. A influência do pensamento socialista, configurado sob a forma de uma dramaturgia realista, tornou-se a pedra de toque para a concretização desse projeto, que se apresentou à sociedade e por ela foi acolhido em suas inovações estéticas e temáticas. As relações entre público e artista se efetivaram como resultantes da identificação da realidade retratada, tendo o realismo crítico como facilitador dessa aproximação e fator de reflexão.

\section{Chapetuba Futebol Clube}

A consolidação de uma dramaturgia com o propósito investigar a realidade social e transformá-la em matéria dramatúrgica, na perspectiva de um aprofundamento na relação teatro-sociedade, será efetivada com a encenação de Chapetuba Futebol Clube, primeira montagem resultante do Seminário de Dramaturgia do Teatro de Arena. Com o propósito de reafirmar o caráter nacional e popular que deve orientar o teatro brasileiro, Vianninha encontra no futebol o universo e os elementos propícios para provocar essa discussão e demarcar o espaço inaugurado por Guarnieri com Eles não usam black-tie.

Embora tratando de temas diversos, as duas peças apresentam traço comum no que diz respeito, particularmente, à 
utilização da dramaturgia realista como instrumento de investigação das realidades social e econômica do país,

[revelando] o interesse pela riqueza e variedade de cores, pela variabilidade e multiplicidade de aspectos da experiência humana. Se a literatura artística de uma época não consegue encontrar a conexão existente entre a práxis e a riqueza de desenvolvimento da vida íntima das figuras típicas de seu próprio tempo, o interesse do público se refugia em sucedâneos abstratos e esquemáticos (LUKÁCS, 2010, p. 162).

Guarnieri traz para a cena o movimento operário, enquanto Vianninha revela os mecanismos do suborno e da corrupção num time de futebol da segunda divisão estadual. As duas peças se utilizam das técnicas do playwriting ${ }^{2}$ em suas estruturas dramatúrgicas, como construção de personagens, curvas de tensão, suspense, etc. É quase inevitável, portanto, estabelecer uma comparação estético-ideológica, tendo como referência Eles não usam black-tie, para se discutir o texto de Vianninha. No entanto, com o propósito de evitar um esquematismo altamente prejudicial à nossa análise, julgamos necessário compreender as condições de produção de cada uma das peças. Portanto, não formulamos aqui nenhum julgamento de valor entre as duas obras.

A peça de Guarnieri surgiu de uma necessidade pessoal do autor e, sendo submetida à direção do grupo, mereceu a encenação. Chapetuba foi escrita com o objetivo de ser submetida a uma análise criteriosa em seus aspectos dramatúrgicos e ideológicos. Foi um processo crítico e autocrítico, promovido pelo seminário, que levou seu autor a reescrevê-la sete vezes. ${ }^{3}$ A peça responde objetivamente aos propósitos estéticos e ideológicos do grupo, não mais como experiência individual e isolada, mas como produto de um processo coletivo de discussão e análise.

Estamos diante da afirmação de uma dramaturgia nacional, que não se satisfaz apenas em trazer para a cena temas brasileiros, reproduzindo uma realidade estática e determinada. $\mathrm{O}$ projeto teórico e dramatúrgico do seminário, observado por Vianninha, tem como objetivo a análise e o entendimento dessa mesma realidade como um processo dinâmico, portanto, sujeito a transformações; uma dramaturgia que pretende discutir um ser humano complexo e capaz de representar sua efetiva participação no jogo das forças sociais, não apenas como receptor passivo, mas, sobretudo, enquanto condição de resposta a esse sistema.

Um teatro brasileiro, então, para mim, será o teatro que vá buscar sua forma e seu conteúdo na realidade específica em que vivemos - não aquele que vai acrescentar vivências e sentimentos a forma que a exprimem, inversamente, como originária da conduta dos homens. Quero fazer um teatro que pretende enriquecer o instrumento do homem, com que ele enfrenta a realidade, permitindo-lhe uma intervenção direta no seio mesmo das próprias condições que originam sua trágica existência - necessariamente trágica pelas condições, não porque suas vontades formam condições; porque as condições formam vontades. Um teatro que distinga a realidade da representação e dos valores que o homem dela tira para a modificação destes mesmos valores, mais aptos para enfrentar as condições que a originaram (PEIXOTO, 1983, p. 73-74, grifo nosso). 
Em Chapetuba, o futebol não é visto apenas como paixão corrompida e manipulada pelo dinheiro, embora este seja o seu tema: a discussão recebe tratamento diferenciado tanto política quanto ideologicamente, pois pretende debater a configuração social frente aos poderosos mecanismos de persuasão e coerção econômica do sistema capitalista em nosso país, por meio da discussão em torno do suborno e da corrupção. O futebol torna-se, assim, um pano de fundo para se discutir aspectos relevantes da realidade brasileira.

Para não se perder no esquematismo e cair numa denúncia que se esgote em si mesma, a peça incorpora elementos do realismo psicológico, sem abrir mão de sua força crítica, e analisa uma sociedade que se encontra em franca transformação, revelando mazelas que se escondem atrás do jogo de interesses capitalistas. Seus personagens são dotados de uma individuação que os torna capazes de agir e reagir aos obstáculos, que lhes são antepostos por situações dramáticas muito bem elaboradas e desenvolvidas. Tudo se explica e tudo está concatenado à ação principal do texto, que, gradativamente, vai ganhando a dramaticidade necessária, caminhando para o seu desfecho quase trágico.

Vianna reafirma a pesquisa empreendida no processo de feitura da peça, com destacada clareza de propósitos, acentuando, inclusive, sem perder a autocrítica, os eventuais defeitos, tanto de composição quanto de abordagem, do material temático. Tal postura nos revela o perfil de um autor que, ainda jovem, não se satisfez com o produto acabado de sua criação, entendendo-o como um processo sempre sujeito à reformulação e ao crivo de uma severa análise.

Chapetuba F. C. tem defeitos graves, de ordem essencial, causados pela ingênua satisfação de muitas vezes permanecer no pitoresco, no detalhe digestivo. Mas Chapetuba $F$. C. tem enorme importância atualmente porque, além de nacional, foi escrita numa tentativa de superar o melodrama jornalístico, a denúncia de efeito, a fala vazia. É cedo para um rendimento satisfatório total. Mas fica a proposta. Tudo que na peça procura a reação fácil, o que fica superficialmente exposto, não é característico, é defeito. Falta de vida. [...] Nunca pretendi fazer de Chapetuba F. C. uma peça estática que imobilize o homem na sua fragilidade e na sua desconfiança. [...] Gostaria de transmitir com esta peça exatamente o transitório, o eterno para a frente, o condicionamento destas vidas a todo um processo da realidade de hoje (VIANNA FILHO, 1981, p. 82-83).

A discussão sobre o caráter popular de Chapetuba não pode, portanto, estar reduzida à introdução do futebol como tema dramático e à mera utilização de representantes das camadas populares como personagens centrais - embora este fato seja de extrema importância ao projeto político e estético do Grupo Arena. O popular se insere, numa relação dialética com o nacional, como apresentação e análise de uma realidade complexa e, como tal, deve merecer um tratamento também complexo. A compreensão dos fatos, por meio do tratamento dado a eles, é fundamental à concretização de uma empreitada revolucionária e transfor- 
madora do teatro, enquanto experiência coletiva, e da própria realidade vigente.

A arte só se torna transformadora a partir da compreensão de que a realidade é transformável, tornando-se, assim, ela mesma, a arte, transformável. Somente a arte de qualidade superior possui o caráter transformador, pois é nela, e somente nela, que o acontecimento humano se realiza em sua plenitude.

Em Chapetuba, o popular não se rebaixa para se impor: é apresentado como uma inovadora formalização estética que valoriza esses temas, encarados, agora, sob uma destacada qualidade dramática, sem que seja necessário apelar a recursos de fácil assimilação. A sofisticação dramática não implica uma eruditização da forma, o que implicaria uma elitização da própria peça e, consequentemente, a elitização da plateia, descartando, assim, a possiblidade de participação popular no acontecimento teatral.

A arte, vigorosa, plena, aprofundando o conhecimento do homem e da realidade, com imagens e símbolos tirados do mundo da consciência popular, abre a verdadeira perspectiva de participação da arte. Não podemos aceitar o dilema que frequentemente nos é colocado - para que haja mensagem, não é possível fazer arte (VIANNA FILHO, 1981, p. 13).

Constata-se que é possível fazer arte popular com qualidade como

[...] parte da autoafirmação, da democratização de nosso pensamento, da afirmação do indivíduo, da responsabilização individual pela sorte da sociedade e tantos outros valores que são defendidos pela consciência popular brasileira (VIANNA FILHO, 1981, p. 14).
A realização dessa qualidade é facilmente verificável nas obras fundadoras do novo teatro que se inaugura e se pretende no Brasil, tendo como ponto de partida as ações do Grupo Arena. No confronto com a realidade, verifica-se um salto qualitativo das nossas dramaturgia e encenação, que credencia esse teatro como popular não por seus recursos rasteiros e de efeitos imediatos, mas por uma formalização artística consciente e de indiscutível qualidade.

Aliada a esse reconhecido valor artístico, é preciso destacar também a qualidade argumentativa de uma nova postura política que passa, então, a figurar em nosso teatro. A apurada consciência crítica de seus autores é fator determinante na construção de uma dramaturgia inquietante e instigadora, que apresenta a reflexão política como resultante do confronto de seus personagens com a realidade, e não como simples manipulação didática de um panfleto. São obras com uma densidade dramática e dramatúrgica, que se colocam entre as melhores já construídas pelo teatro brasileiro.

[...] à atitude criadora que cada vez mais caracteriza todo nosso pensamento político, deverá corresponder uma criadora atitude no teatro, que recebe com violência os golpes imediatos dos fatos, estando em estreito contato artístico e financeiro com platéias que, como nunca talvez, exigem o debate de sua própria condição, a fundamentação de seus objetivos e de sua filosofia que vai sendo arrebanhada no dia-a-dia (VIANNA FILHO, 1981, p. 87-88).

Chapetuba se propõe a realizar uma investigação da realidade em seus aspec- 
tos condicionantes das relações humanas e promove um entendimento sobre alguns mecanismos de opressão capitalista perceptíveis na sociedade brasileira. Discutir o suborno no futebol é bem mais que discutir a compra do resultado de um jogo de decisão de campeonato: é revelar fraturas de um sistema que, em suas contradições e conivências, não se constrange em destruir sonhos e frustrar esperanças.

Para analisar a determinação econômica sobre o homem, Vianninha encontra num time de futebol da segunda divisão os elementos necessários para entender essa engrenagem, trazendo para dentro da peça, por meio da configuração dialética do interno e do externo, todo um processo social, determinando o comportamento dos personagens e o desenvolvimento dos acontecimentos dramáticos. Adorno esclarece a relação dialética entre arte e realidade no processo de representação:

A arte nega as determinações categorial-
mente impressas na empiria e, no entanto,
encerra na sua própria substância um ente
empírico. Embora se oponha à empiria atra-
vés do momento da forma - e a mediação da
forma e do conteúdo não deve conceber-se
sem a sua distinção - importa, porém, em
certa medida e geralmente, buscar a media-
ção no fato de a forma estética ser conteúdo
sedimentado (ADORNO, [197-?], p. 15).

Chapetuba, sob a perspectiva do realismo crítico, método que permite uma análise objetiva das relações humanas, traz para a cena a representação de uma sociedade complexa que assimila o capitalismo e subordina o homem aos seus ditames. A realidade concre- ta dramatizada revela que uma força superior comanda as relações sociais e humanas, e encontramos aí os dados que nos permitem compreender os processos capitalistas de dominação: a máquina é acionada, e o homem é absorvido e vê os seus sonhos esmagados.

O que está em jogo é mais do que o acesso à divisão de elite do futebol estadual, é a dignidade humana que não consegue resistir à força do dinheiro. É o sonho desfeito, que não se realiza porque uma engrenagem de interesses é colocada em movimento, e ela não conhece, como também não respeita, sentimentos. $\mathrm{O}$ microcosmo que envolve o acesso à primeira divisão do futebol estadual é um espaço privilegiado para que as relações dialéticas sonho e realidade, corruptor e corrupto, indivíduo e coletivo se manifestem e se enfrentem em constante conflito: suas contradições são determinadas pelas relações sociais. Interesses diversos se manifestam e induzem a um processo de reflexão sem, necessariamente, o autor tomar essa ou aquela posição.

O dinheiro é, de maneira direta ou indireta, o grande articulador de relações entre personagens e as ações principal e secundárias da peça. Dramaticamente, as relações que envolvem o dinheiro se movem a partir da dependência mais imediata que os personagens manifestam, reforçando sua importância, conferindo-lhe um status de leitmotiv. ${ }^{4}$ Chapetuba é um time de futebol, mas é também uma cidade inteira. O futebol torna-se, 
assim, uma atividade de interesse público, não só em seu aspecto emocional, como também no que pode representar para o futuro daquela comunidade. $\mathrm{O}$ sonho contamina a todos, e a cidade se mobiliza por um resultado positivo:

Eunápio - Chapetuba está tremendo, gente! Nossa! Nunca vi isso! O orgulho dessa Chapetuba, sem nada, nunca nada, é vocês, gentada! (VIANNA FILHO, 1981, p. 97). ${ }^{5}$

O dinheiro, porém, não move apenas as pessoas em suas individualidades: além do grande destaque que Chapetu$\mathrm{ba}^{6}$, a cidade, alcança, tendo o seu time disputando jogos nos principais estádios de São Paulo e recebendo também os grandes em seus gramados, a decisão do campeonato movimenta a economia, que vê na conquista do título reais possibilidades de crescimento em seu comércio:

Eunápio - Conheço dois tipos que abrem loja aqui com Chapetuba campeão... (VIANNA FILHO, 1981, p. 98).

Os jogadores são alçados ao status de verdadeiros heróis: de sua vitória se escreverá um novo futuro; sua conquista está para além do título de campeão. As condições são todas favoráveis: a decisão é em casa, conta com o apoio da torcida. $\mathrm{O}$ entusiasmo é tanto que até mesmo contribuições financeiras foram conseguidas para premiar os jogadores - o bicho.

Eunápio - Ninguém largou mão de contribuir na lista pro Chapetuba. Olha aí... Lotadinha! O Zé Pidão deu dez mil réis! Chapetuba acendeu feito de noite! A última vez somei oitenta conto... oitenta e três... há, há!
Cafuné - Oitenta conto, de dinheiro?

$[\ldots]$

Eunápio - Oitenta contos! Oitenta contos!

Cafuné - Tudo pra nóis! Ai!

Todos - Ganhando, Funé.

Cafuné - (Transição) Ai... (VIANNA FILHO, 1981, p. 97-98).

Outros interesses, porém, estão colocados, e um jogo paralelo e simultâneo se estabelece na disputa pelo resultado final da partida, agora fora de campo: Saboeiro, a cidade do time rival, maior e mais rica que Chapetuba, também se interessa pela vitória do campeonato. Nesse quadro, a ordem que se impõe é determinada pelos lucros que se pode obter com o futebol da primeira divisão. O poder econômico de Saboeiro, aliado aos interesses da federação estadual de futebol, irá lançar mão de todos os expedientes disponíveis, no sentido de favorecer o time Saboeiro. Nessa articulação, não existe ética.

Para todo corruptor, em maior ou menor escala, haverá alguém que se preste a fechar o círculo e permitir que a corrupção se efetive. Benigno é um corrupto profissional - o homem da mala preta. Suas relações com o futebol envolvem sempre o suborno, a compra de resultados. Seu alvo mais uma vez é Maranhão, goleiro do Chapetuba, que traz uma nódoa em sua história, pois já se vendeu. 
Benigno - Já tá perdido, Maranha. Me entende! Ninguém desconfia, rapaz. Até hoje em Saboeiro ninguém diz que você se vendeu! Ninguém desconfiou daquele pulo... Cê disfarça bem. Pula bonito. A bola entra. Ninguém diz nada... (VIANNA FILHO, 1981, p. 108).

Embora Maranhão queira dar a volta por cima, manifestando clara vontade de vencer o campeonato, o seu momento não é o melhor: a oportunidade que se lhe apresenta é bastante tentadora. Na primeira tentativa de suborno de Benigno sobre "o arqueiro menos vazado da segunda divisão de profissionais" (VIANNA FILHO, 1981, p. 104), podemos verificar que o futebol, na peça colocado como representação do macrocosmo social, está pressionado por interesses econômicos e a eles subordinado. A apresentação do conflito principal da peça instaura também, no âmbito dramático, as relações sociais mais amplas do processo de dominação capitalista:

Benigno - Todo mundo quer o Saboeiro na primeira divisão.

Maranhão - Todo mundo menos eu...

Benigno - Todo mundo quer o Saboeiro, Maranha. Juro! Saboeiro dá mais renda...

[...]

Benigno - A Federação não vai aceitar, Maranha. Ouve... vai dizê assim: "o estádio do Chapetuba é muito pequeno!". "Num é, não!”. “Tá bem”. Então, diz: a inscrição de fulano de tal num corresponde... Vai descobri qualqué coisa até enterrá teu time na papelada suja. É. Dá vontade de contá tudo por aí... A Federação prefere Saboeiro. Café, mais café, e café: dinheiro. Cheguei. A Federação prefere Saboeiro.

[...]

Benigno - [...] O juiz é da Federação, Maranha. Ele come por causa dela...

Maranhão - Uma mentira sua, Benigno.

Benigno - Eu vinha de Saboeiro menti pra você, Maranhão? Oitenta quilometro?

Maranhão - Nenhum juiz vai fazê moamba nesse jogo. Falta peito.

Benigno - Vem todo mundo de Saboeiro vê o jogo, Maranhão. Eles querem o Saboeiro no Pacaembu. Querem o São Paulo e o Coríntia em Saboeiro (VIANNA FILHO, 1981, p. 105-108).

Maranhão deve quatro meses de aluguel à pensão onde mora; deve uma quantia a Eunápio; e deve ainda mil reis a um tal Tomáz; o que, para os seus padrões atuais, não é uma quantia irrisória. Durval, em uma das mais importantes cenas da peça, lembra o companheiro da dívida e, como pressentindo alguma coisa, discute também o seu possível envolvimento com Benigno.

Durval - Um sujeito te procurou no campo. Que tu deve pra ele...

Maranhão - Tomáz.

Durval - Isso. Tomáz. Muito dinheiro?

Maranhão - Mil réis.

Durval - Então o escândalo foi de fita! Eu sô como tu, nenê. Dinheiro é pra gastá. A gente sempre dá um jeito de se arrumá, não é? 
Maranhão-Que jeito?

Durval - Tu já trabalhou com o Benigno?

Maranhão - Vê lá. Nunca precisei disso.

Durval - Eu já. Foi besteira que fiz, Maranhão. Tinha perna pra continuá sozinho. Depois eles não querem largar, não é? (VIANNA FILHO, 1981, p. 116).

A engrenagem não visa apenas a Maranhão, existe uma rede de corrupção atuando em torno da decisão do campeonato: a federação tem interesses claros na vitória de Saboeiro - um estádio maior, maior renda; mais renda, maior lucro - e se articula para se garantir. Nos últimos minutos da partida, o árbitro marca um pênalti inexistente, que define o resultado. Benigno é apenas um testa de ferro; Maranhão, apenas uma peça no tabuleiro, certamente a mais fraca, um peão, mas que pode ser decisivo no xeque-mate. Todo o sistema está protegido e preparado.

No início do segundo ato, Benigno faz uma nova investida e dobra a oferta de dinheiro. É sua última participação na peça e deixa para Maranhão a dúvida. O goleiro não é forte o suficiente para resistir aos assédios e às pressões de Benigno: simula uma contusão e não participa do jogo.

A peça inicia-se com um jogo de damas: Maranhão e Bila disputam uma partida. Maranhão impõe ao goleiro reserva um curé. ${ }^{7}$ Bila substitui Maranhão no jogo. Chapetuba perde o campeonato. Com esta cena de abertura, Vianninha apresenta o grande jogo da peça: aquele que se estabelece fora das quatro linhas. Ao colocar os dois goleiros - titular e reserva - se enfrentando ludicamente, antecipa (ainda que somente o percebamos ao final) uma estrutura que se constrói e se efetiva de acordo com interesses específicos. Os dois personagens são transformados em peças de um tabuleiro em que as verdadeiras mãos que os manipulam não se revelam.

Maranhão não é o grande vilão da peça; tampouco Bila pode ser considerado culpado pelo resultado que mantém Chapetuba na segunda divisão. Maranhão e Bila são, cada um ao seu modo, inocentes úteis, representando o papel que lhes cabe nesse jogo impessoal da corrupção, no qual se manifesta a luta de classes em que, de um lado, temos os representantes populares trabalhadores e, do outro, o poder econômico representando a classe dominante. Nessa luta, travada no interior do sistema capitalista, o trabalhador é mais uma vez derrotado.

A dimensão humana que desenha os personagens-pivôs é a mesma que se revela em cada um daqueles jogadores de Chapetuba Futebol Clube. Seus personagens são seres humanos esmagados em seus sonhos, privados de experimentar a vida em sua plenitude, pois sempre vai lhes faltar alguma coisa. Ainda que tentem sonhar, a realidade se lhes apresenta com toda sua aspereza, interrompendo o momento lúdico no qual compartilham frágeis esperanças. Cada um tem sua razão e seus medos, suas expectativas 
e seus mistérios. Todas as ações estão plenamente justificadas pelo movimento psicológico dos personagens e pela integridade dramática da trama. Esse desvelo pelos personagens, cuidando de sua humanidade, se converte em marca da dramaturgia de Vianninha, que sempre permite as mais profundas contradições e conflitos humanos às suas criaturas.

Chapetuba definia por antecipação uma das vertentes da obra do autor, a mais significativa, que escarafuncha as motivações profundas do ser humano, traçando uma radiografia solidária do calvário do indivíduo contemporâneo, fiel aos valores éticos e pressionado por um mundo esvaziado (ZANOTTO, 1981 apud PATRIOTA, 2007, p. 100).

Mesmo a opção do Arena por uma estética realista/naturalista, ${ }^{8}$ o que acentuaria o caráter nacional e popular das peças, não impediu Vianninha de desenvolver uma forma própria de diálogos, imprimindo-lhes uma identidade formal que marcaria toda sua dramaturgia. Segundo o autor, há clara influência do modo de escrever do seu pai: "eu tenho impressão que a influência é direta até no tipo de tratamento, no tipo de diálogo, um pouco sincopado, uma série de coisas que o meu pai teve como característica" (VIANNA FILHO, 1960 apud PEIXOTO, 1983, p. 36-37).

Não é, portanto, esse apuro formal determinante de um menor apreço pela humanidade de seus personagens: pressionados pelas forças sociais, não perdem sua natureza, como, tampouco, se esquematizam para servir como instrumento de denúncia.

\section{Considerações finais}

O capitalismo esmaga todos, mas nenhuma palavra é dita contra o capitalismo: um dos méritos de Chapetuba é o de não ceder ao panfletário e assumir uma denúncia escancarada ao suborno e à corrupção, preservando, assim, a autonomia da arte. Sua força dramática supera qualquer vacilo nesse sentido: a ação se sustenta nos conflitos humanos e unicamente a eles deve o seu desenvolvimento.

[Chapetuba...] carrega as preocupações mais duradouras do autor, que considerava importante a denúncia, mas que nunca se satisfez apenas em denunciar. Um autor preocupado - mais do que qualquer outro entre nós - com a origem das "falhas" que determinam os conflitos de seus personagens, uma galeria de torturados consigo mesmos. Maranhão e Durval são apenas os primeiros dessa galeria. Os dois chegam a carregar um certo "segredo", particularmente Maranhão, no sentido de não revelarem muito abertamente a razão de suas "falhas". Nem para si mesmos. Vianna quis dar-lhes a inconsciência de suas limitações. Sabem que falharam, sofrem por isso, mas não sabem como resolver. Esse tipo de conflito me parece típico na obra do Vianna. Mais tarde, em níveis mais profundos e diferenciados, essa mesma necessidade de colocar o homem diante de si mesmo, no espelho, vai aparecer nas obras mais maduras. Uma característica do homem preocupado profundamente com as dificuldades, com as limitações, com os obstáculos que o homem brasileiro encontra para levar a cabo com êxito a sua libertação política e social (XAVIER, 1981, p. 85).

A realidade refletida e refratada nos seus personagens se materializa enquanto arte e, configurada dramaticamente, revela-nos o seu próprio interior. Os conflitos dos personagens, o suborno e 
a corrupção, agora dramatizados, estão subordinados à ação e a ela, exclusivamente, devem o seu movimento, sem se colocarem acima dos dramas vividos pelos personagens enquanto discurso do autor contra o sistema em questão.

Participação na arte, para nós, exige em primeiro lugar a realização plena da obra de arte. Ou seja, as significações que ela pretende extrair do mundo, a mensagem que ela pretende deixar, deve estar resolvida dentro de si mesma, a partir dos estímulos sensíveis que ela organiza. Não há que, em nome da participação, baixar o nível artístico das obras de arte, diminuir sua capacidade de apreensão sensível do real, estreitar a riqueza de emoções e significações que ela pode emprestar (VIANNA FILHO, 1981, p. 13). ${ }^{9}$

\section{Représentations du capitalisme à Chapetuba Futebol Clube, de Oduvaldo Vianna Filho}

\section{Résumé}

Chapetuba Futebol Clube, la première pièce de Oduvaldo Vianna Filho - Vianninha - organisé par le Grupo de Teatro Arena, il se distingue par sa valeur dramaturgique et son importance dans l'analyse de la réalité sociale brésilienne. Dans cet article, nous essayons de surmonter la critique traditionnelle, qui ne voit que le binôme captation / corruption dans le football reflète la société, pour répondre aux configurations des mécanismes de l'oppression capitaliste nommés par le dramaturge. En tant que méthode d'analyse, nous utilisons la critique matérialiste et dialectique, soutenue par les études de Lukács et Adorno, visant à établir la relation de détermination mutuelle entre l'art et la société, ayant dans le conditionnement historique les bases de la configuration artistique. Chapetu$b a$ investit dans le réalisme critique en tant qu'alternative esthétique et formelle pour essayer de comprendre un instant de profonds changements sociaux, politiques et économiques survenus dans la seconde moitié des années 1950, caractérisés comme «développementalisme national». Dans le jeu, le football est non seulement considéré comme passion corrompu et manipulé par l'argent, bien que ce soit son thème: la discussion obtient un traitement spécial, à la fois politiquement et idéologiquement, car il a l'intention de discuter de défi contexte social les mécanismes de persuasion puissants et la coercition économique le système capitaliste dans notre pays, à travers la discussion sur la corruption et la corruption.

Mots-clés: Drame brésilien. Le théâtre engajée. Oduvaldo Vianna Filho.

\section{Notas}

1 Fundado em 05 de abril de 1955.

2 Conjunto de técnicas específicas da construção dramatúrgica, como composição de cena, diálogos, personagens, desenvolvimento da ação dramática, etc. Como bem ressalta Pavis, "A escritura contemporânea, especialmente a pós-dramática e pós-brechtiana, não mais obedece a uma série de regras de composição" (PAVIS, 2011, p. 62-63).

3 Em entrevista a Alfredo Souto de Almeida, Vianninha esclarece: "essa peça no Seminário de Dramaturgia passou por quase sete versões" (PEIXOTO, 1983, p. 39).

4 Leitmotiv é o tema central da peça, que pode se manifestar de diversas maneiras, por meio de gestos que se repetem, ou de temas ou de atitudes de personagens. No caso em questão, cabe ressaltar que a discussão em torno do dinheiro é um traço marcante na obra de Vianninha. Várias de suas peças - como, por exemplo, Bilbao 
via Copacabana; A mais-valia vai acabar, seu Edgar; Corpo a corpo; Allegro desbum - terão o dinheiro como agente de grande destaque em suas tramas.

5 Embora a ABNT estabeleça e as normas da revista determinem que toda citação com menos de quatro linhas seja integrada ao corpo do texto, optamos por, no caso das citações de diálogos da peça, colocarmos em recuo visando a manter as características específicas da literatura dramatúrgica.

6 Sempre que nos referirmos à peça e ao time de futebol, utilizaremos a grafia em itálico, Chapetuba; para designar a cidade, utilizaremos Chapetuba, em grafia normal. Utilizaremos a mesma diferenciação para Saboeiro (cidade) e Saboeiro (time).

7 Em jogo de damas, significa deixar a pedra do adversário sem possibilidade de saída. Equivale ao xeque-mate no xadrez.

8 A opção por uma dramaturgia realista/naturalista pode ser verificada nas duas peças - Eles não usam black-tie e Chapetuba Futebol Clube - não só na temática, mas também na estrutura dramatúrgica: ambas são compostas em três atos, com a utilização do tradicional desenvolvimento linear e cronológico da ação dramática e da construção psicológica dos personagens.

$9 \quad$ Marx e Engels já haviam alertado para o perigo da instrumentalização da arte em detrimento da qualidade artística e a utilização do engajamento como desculpa: "Torna-se cada vez mais um hábito, particularmente dos tipos inferiores de literati, compensar a falta de inteligência de suas produções com alusões políticas que certamente atraem a atenção. Poesia, romances, críticas, drama, toda produção está cheia do que era chamado de tendência" (1851 apud WILLIAMS, 1979, p. 198).

\section{Referências}

ADORNO, Theodor W. Teoria estética. Trad. Artur Morão. Lisboa: Edições 70, [197-?].

BRECHT, Bertolt. Teatro Dialético. Trad. Luiz Carlos Maciel. Rio de Janeiro: Civilização Brasileira, 1967.

DIONYSOS N ${ }^{\circ}$ 24. Especial: Teatro de Arena. Rio de Janeiro: MEC/DAC-Funarte/ SNT, 1978.
GUARNIERI, Gianfrancesco. Teatro de Gianfrancesco Guarnieri 1. Rio de Janeiro: Civilização Brasileira, 1978.

FISCHER, Ernst. A necessidade da arte. 9. ed. Trad. Leandro Konder. Rio de Janeiro: Zahar, 1983.

LUKÁCS, György. Marxismo e teoria da literatura. São Paulo: Expressão Popular, 2010. MOSTAÇO, Edélcio. Teatro e política: Arena, Oficina e Opinião - uma interpretação da cultura de esquerda. [São Paulo]: Proposta Editorial, 1982.

PATRIOTA, Rosangela. A crítica de um teatro crítico. São Paulo: Perspectiva, 2007.

PAVIS, Patrice. Dicionário de teatro. 3. ed. Trad. J. Guinsburg et al. São Paulo: Perspectiva, 2011.

PEIXOTO, Fernando (Sel., org. e notas). Vianinha - teatro, televisão, política. São Paulo: Brasiliense, 1983.

VIANNA FILHO, Oduvaldo. Oduvaldo Vianna Filho /1: teatro. Org. Yan Michalski. Rio de Janeiro: Edições Muro, 1981.

WILLIAMS, Raymond. Marxismo e literatura. Trad. Valtensir Dutra. Rio de Janeiro: Zahar, 1979.

XAVIER, Nelson. A necessidade de ser brasileiro. In: VIANNA FILHO, Oduvaldo. Oduvaldo Vianna Filho/1: teatro. Org. Yan Michalski. Rio de Janeiro: Edições Muro, 1981. p. 81-85. 